\title{
Midazolam Premedication with Sevoflurane on Quality and Cost of Anaesthesia in Paediatric Day Case Surgery
}

\author{
Md. Arif Uddin ${ }^{1 *}$, Md. Shafiqul Islam², Md. Abdur Rahim³ ${ }^{3}$ Kazi Mahzabin Arin ${ }^{4}$, AKM Akhtaruzzaman ${ }^{5}$
}

\author{
${ }^{1}$ Junior Consultant (Current Charge), 100 Bed Burn Unit, Dhaka Medical College Hospital, Dhaka, Bangladesh \\ ${ }^{2}$ Associate Professor, Department of Anaesthesia, Analgesia and Intensive Care Medicine, Bangabandhu Shiekh Mujib Medical University, Dhaka, \\ Bangladesh \\ ${ }^{3}$ Registrar, Cardiac Anaesthesia, National Heart Foundation and Research Institute, Dhaka, Bangladesh \\ ${ }^{4}$ Assistant surgeon, OSD (DGHS), Attachment- Jessore 250 Beded District Sadar Hospital, Jessore, Bangladesh \\ ${ }^{5}$ Professor, Department of Anaesthesia, Analgesia and Intensive Care Medicine, Bangabandhu Shiekh Mujib Medical University, Dhaka, Bangladesh
}

DOI: $10.36347 /$ sjams.2020.v08i09.012

| Received: 03.09.2020 | Accepted: 11.09.2020 | Published: 17.09.2020

*Corresponding author: Md. Arif Uddin

Abstract

Original Research Article

Objective: The Objective of the study was to evaluate the quality and cost-effectiveness of inhalation anaesthesia by sevoflurane using midazolam as premedication compared to using sevoflurane alone in paediatric patients. Method: This double blinded randomized clinical trial was conducted among 120 patients aged 1-7 years undergoing routine elective paediatric day case surgery of under 60 minutes of duration at the Department of Anaesthesia, Analgesia and Intensive Care Medicine, BSMMU, Dhaka during the period of May 2018 to september 2018. Results: During the study, the patients were randomly allocated into two equal groups-Group A (60 patients) and Group B (60 patients). The children of the experimental group (Group B) received orange juice containing $0.5 \mathrm{mg} / \mathrm{kg}$ of oral midazolam. Perioperative blood pressure and heart rate were measured by standard monitors and recorded periodically. Induction of both groups was done by inhalation of $4 \%$ sevoflurane with fresh gas flow. Recovery profile of patients was measured by Modified Ramsay Sedation Score to observe any emergence of anaesthesia. Mean age of group A and group B patients were 3.76 \pm 1.21 and $4.06 \pm 1.32 \mathrm{SD}$ (years) respectively, with male predominance (male $92.5 \%$ vs female $7.5 \%$ ). In terms of parent separation characteristics group B were more comfortable (76.7\% vs $11.7 \%)$ than group $\mathrm{A}$ and this finding was significant $(\mathrm{p}<0.001)$. Haemodynamic stability of patients were significantly higher in sevoflurane + midazolam group (group B) than group A $(\mathrm{p}<0.001)$, sevoflurane consumption rate and the cost of anaesthetic agent were observed between two groups and reduced consumption rate observed in group B and significantly reduced cost of sevoflurane observed in group B $(\mathrm{p}<0.001)$. Midazolam premedication with sevoflurane used in Paediatric day surgery may improve the quality of anaesthesia as they had lower incidence of difficult parent separation, makes the patients hemodynamically more stable and lower the incidence of emergence in recovery time. Conclusion: From our results we can conclude that, Premedication with midazolam provided better parent separation criteria, smooth induction and post-operative recovery. Moreover, sevoflurane consumption was lesser with lower cost in these group compared to control.

Keywords: Haemodynamic, anaesthesia, sevoflurane, midazolam.

Copyright @ 2020: This is an open-access article distributed under the terms of the Creative Commons Attribution license which permits unrestricted use, distribution, and reproduction in any medium for non-commercial use (NonCommercial, or CC-BY-NC) provided the original author and source are credited.

\section{INTRODUCTION}

Sevoflurane is a relatively newer inhalational anaesthetic agent which is used for both induction and maintenance of general anaesthesia. After usage of many years it has an excellent safety record. It is one of the most commonly used volatile anaesthetic agents, particularly for outpatient anaesthesia across all ages [1].

In spite of many advantages sevoflurane is not widely used in our country mainly because of it's high cost. For many years, halothane has been used as a chief inhalational agent in paediatric anaesthesia specially in third world countries because of low cost and anaesthetic potency. But children do not want to take breath and they fight when mask ventilation is attempted with halothane. Often complications like breath holding, laryngospasm occurs during induction and recovery. On the other hand, favourable characteristics have made sevoflurane a suitable agent for paediatric anaesthesia [2].

High cost of sevofurane remains a area of great concern for anaesthesiologist. Sedative premedication 
can be safe alternative to reduce the consumption of sevoflurane. Among sedative agents midazolam is a short acting benzodiazepine that is very lipophilic in physiological $\mathrm{pH}$, which contributes to its rapid onset of action [3]. Midazolam given before induction of anesthesia is safe and effective [4]. Midazolam has been shown to induce satisfactory sedation and anxiolysis within 20 minutes of administration [5]. So, the consumption of sevoflurane should be less which may reduce its cost to some extent.

Another area of concern in paediatric anaesthesia is preoperative anxiety and stress. It is estimated that nearly $70 \%$ of all children show significant stress and anxiety before surgery [6]. Reasons behind this behavioral response may be due to child's perception of the threat of bodily discomfort or harm, the threat of being separated from parents, the fear of unknown and strange environment and the threat of losing control and autonomy [7]. Extreme anxiety and stress before surgery has also been reported to result in negative postoperative sequel like emergence delirium, maladaptive behavior, and increased postoperative pain [8].

Currently three major preoperative modalities for the reduction of anxiety in children: behavioral preparation programs of various kinds, parental presence during induction of anaesthesia (PPIA), and sedative premedication [9].

Multiple randomized control trials studies considering less literature in this topic, the study was designed to assess the effect of midazolam premedication on quality and cost of anaesthetic agent using sevoflurane in paediatric day case surgery in a tertiary care hospital of Bangladesh.

Multiple randomized control trials studies have found that midazolam is far better than behavioral preparation program in terms of preoperative anxiety and compliance during induction of anaesthesia [10].

\section{OBJECTIVES OF THE STUDY General Objective}

Evaluation of quality of anesthesia and consumption of sevoflurane using midazolam premedication in paediatric day case surgery

\section{Specific Objectives}

- To observe parent separation characteristics by parent separation scale in each group.

- To measure blood pressure, heart rate by a standard monitor in both groups.

- To measure amount of sevoflurane consumed in each groups.

- To compare parent separation characteristics, haemodynamic criterias like blood pressure, heart rate, and amount of sevoflurane consumption with cost analysis between the two groups.

\section{Methodology \\ Study type}

- This was an prospective double blinded randomized clinical trial

\section{Study place and period}

- Department of Anaesthesia,Analgesia and Intensive Care Medicine, BSMMU from May 2018 to September 2018

\section{Sampling method}

- The sample was collected by random sampling

\section{Study population}

- All patients aged 1-7 years attending at the department of Anaesthesia, Analgesia and Intensive Care Medicine, BSMMU for routine day case paediatric surgery of less than one hour duration were enrolled.

\section{Inclusion criteria}

- Children of 1-7 years of age

- Children scheduled for routine day case surgery of less than one hour duration under general anaesthesia.

- Patient with ASA (American Society of Anesthesiologist) grade I \& II

\section{Exclusion criteria}

- $\quad$ ASA grade III \& IV

- Emergency surgery.

- Known allergic to midazolam.

- Diagnosed central nervous system disorders.

- Diagnosed neuromuscular disease.

\section{Procedure of data collection}

All the data were collected in a preformed questionnaire. Following data collection, they were noted down in the questionnaire. After that, all were transcribed into the statistical software.

\section{Statistical Analysis}

Statistical analysis was carried out using the Statistical Package of Social Sciences version 21.0. Exploratory data analysis were carried out to describe the study population where categorical variables were summarized using frequency tables while continuous variables were summarized using measures of central tendency and dispersion such as mean, median and standard deviation. Age and sex difference across the groups were determined by student's $t$-test. Comparison of numerical variables was done using Student's t-test. Parent separation characteristics of patients and haemodynamic stability of patients between two groups were determined by chi-square test. Moreover, anesthetic and post-anaesthetic recovery profile of 
patients and Sevoflurane consumption amount between two groups were determined by unpaired student's $t$ test. P-value $<0.05$ was considered statistically significant.

\section{RESULT}

Patients aging 1 to 7 years were considered for inclusion. Mean age of total population was 3.91 \pm 1.27 years. Mean age of group A and group B patients are respectively $3.76 \pm 1.21$ and $4.06 \pm 1.32$ years. Majority of the children were aged 3 years. Among group a patients, majority were aged 3 years and among group B patients, majority were aged 5 years. There were no statistically significant difference in age distribution between two groups $(\mathrm{p}>0.05)$.

Table-I: Age distribution of study population $(n=120)$

\begin{tabular}{|l|l|l|}
\hline Age, years & $\begin{array}{l}\text { Group A } \\
(\mathbf{n = 6 0})\end{array}$ & $\begin{array}{l}\text { Group B } \\
(\mathbf{n = 6 0})\end{array}$ \\
\hline Age (mean \pm SD) & $4.06 \pm 1.32$ & $3.76 \pm 1.21$ \\
\hline Years & $\mathrm{n}(\%)$ & $\mathrm{n}(\%)$ \\
\hline 2 & $8(13.3)$ & $8(13.3)$ \\
\hline 3 & $14(23.3)$ & $20(33.3)$ \\
\hline 4 & $14(23.3)$ & $16(26.7)$ \\
\hline 5 & $16(26.7)$ & $12(20.0)$ \\
\hline 6 & $6(10.0)$ & $2(3.3)$ \\
\hline 7 & $2(3.3)$ & $2(3.3)$ \\
\hline
\end{tabular}

$p$ value determined by respectively *unpaired Student's $t$ test

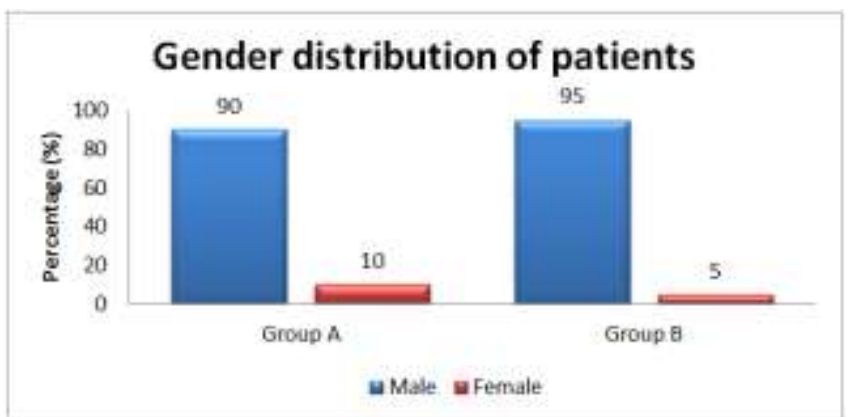

Fig-1: Gender distribution of patients $(n=120)$

Table II shows that mean weight of all patients were $14.64 \pm 3.48 \mathrm{~kg}$. Among group A and group B patients, majority had weight between $11-15 \mathrm{~kg}$ (respectively $48.3 \%$ and $53.3 \%$ ). Distribution of weight were similar across groups.

Table-II: Weight distribution of study population $(n=120)$

\begin{tabular}{|l|l|l|l|l|}
\hline $\begin{array}{l}\text { Weight, } \\
\text { (in Kg) }\end{array}$ & $\begin{array}{l}\text { Group A } \\
(\mathbf{n = 6 0})\end{array}$ & $\begin{array}{l}\text { Group B } \\
(\mathbf{n = 6 0})\end{array}$ & $\begin{array}{l}\text { Total } \\
(\mathbf{n = 1 2 0})\end{array}$ & p value \\
\hline Weight (mean \pm SD) & $14.75 \pm 3.60$ & $14.53 \pm 3.39$ & $14.64 \pm 3.48$ & $.735^{*}$ \\
\hline $\begin{array}{l}\text { Weight group } \\
\text { (in Kg) }\end{array}$ & $\mathrm{N}(\%)$ & $\mathrm{N}(\%)$ & $\mathrm{N}(\%)$ & \\
\hline $6-10$ & $7(11.7)$ & $6(10.0)$ & $13(10.8)$ & \\
\hline $11-15$ & $29(48.3)$ & $32(53.3)$ & $61(50.8)$ & $.828^{* *}$ \\
\hline $16-20$ & $20(33.3)$ & $20(33.3)$ & $40(33.3)$ & \\
\hline $21-25$ & $4(6.7)$ & $2(3.3)$ & $6(5.0)$ & \\
\hline
\end{tabular}

$p$ value determined by respectively *unpaired Student's $t$ test and $* *$ Chi-squared test

Among group a patient's $88.3 \%$ were uncomfortable and among group B patients $23.3 \%$ were uncomfortable. The difference between groups were statistically significant $(\mathrm{p}<.001)$. Group B patients comprised significantly more comfortable patients than group A (76.7 vs 11.7, p<.001). 
Table-III: Parent separation characteristics of patients between two groups $(n=120)$

\begin{tabular}{|l|l|l|l|}
\hline \multirow{2}{*}{$\begin{array}{l}\text { Characteristics } \\
\text { With scoring }\end{array}$} & $\begin{array}{l}\text { Group A } \\
\text { (n=60) }\end{array}$ & $\begin{array}{l}\text { Group B } \\
\text { (n=60) }\end{array}$ & \multirow{2}{*}{ p value } \\
\cline { 2 - 3 } & $\mathbf{n ( \% )}$ & $\mathbf{n}(\mathbf{\% )})$ & \\
\hline Uncomfortable & $\mathbf{5 3 ( 8 8 . 3 )}$ & $\mathbf{1 4 ( 2 3 . 3 )}$ & \multirow{2}{*.001}{} \\
\hline Inconsolable cry (0) & $37(61.7)$ & $4(6.7)$ & \\
\hline Complaining (1) & $16(26.7)$ & $10(16.7)$ & \\
\hline Comfortable & $\mathbf{7 ( 1 1 . 7 )}$ & $\mathbf{4 6 ( 7 6 . 7 )}$ & \multirow{2}{*.001}{} \\
\hline Quiet but awake (2) & $5(8.3)$ & $12(20)$ & \\
\hline Sleepy (3) & $2(3.3)$ & $34(56.7)$ & \\
& & & \\
\hline
\end{tabular}

$\mathrm{p}$ value determined by Chi-Square test

Peri-operative haemodynamic parameters including heart rate, blood pressure and percentage saturation of oxygen was monitored, and recorded in each patients before induction, ten minutes after induction and twenty minutes after induction. Perioperative heart rate and blood pressure were significantly lower in group B patients in comparison to group a patients. Pre-operative saturation of oxygen was significantly low in group B patients than group patients, but the differences vanished after induction. Saturation of oxygen remained stable during operation (Table IV).

Table-IV: Haemodynamic stability of patients between two groups $(n=120)$

\begin{tabular}{|l|l|l|l|}
\hline \multirow{2}{*}{$\begin{array}{l}\text { Variables for haemodynamic } \\
\text { Stability }\end{array}$} & $\begin{array}{l}\text { Group A } \\
(\mathbf{n = 6 0 )}\end{array}$ & $\begin{array}{l}\text { Group B } \\
(\mathbf{n = 6 0 )}\end{array}$ & \multirow{2}{*}{ p value } \\
\cline { 2 - 3 } & Mean \pm SD & Mean \pm SD & \\
\hline Perioperative Heart rate, beats/min & & & \\
\hline Ten minutes after induction & $85.56 \pm 7.59$ & $78.80 \pm 5.58$ & $<.001$ \\
\hline Twenty minutes after induction & $87.45 \pm 7.58$ & $76.61 \pm 4.93$ & $<.001$ \\
\hline Perioperative Blood Pressure, $\mathrm{mmHg}$ & & & \\
\hline Systolic blood pressure & & & \\
\hline Ten minutes after induction & $94.91 \pm 3.57$ & $84.81 \pm 4.45$ & $<.001$ \\
\hline Twenty minutes after induction & $92.58 \pm 3.66$ & $84.55 \pm 4.56$ & $<.001$ \\
\hline Diastolic blood pressure & & & \\
\hline Ten minutes after induction & $64.48 \pm 3.95$ & $55.05 \pm 4.26$ & $<.001$ \\
\hline Twenty minutes after induction & $63.21 \pm 4.12$ & $54.03 \pm 7.46$ & $<.001$ \\
\hline
\end{tabular}

$\mathrm{P}$ value determined by Chi-square test

Table-V: Post-anaesthetic recovery profile of patients between two groups $(n=120)$

\begin{tabular}{|l|l|l|l|}
\hline Patient recovery profile & $\begin{array}{l}\text { Without midazolam } \\
\text { N=60 } \\
\mathbf{n}(\%)\end{array}$ & $\begin{array}{l}\text { With midazolam } \\
\mathbf{N = 6 0} \\
\mathbf{n}(\%)\end{array}$ & P value \\
\hline Anxious and Restless & $43(71.7)$ & $7(11.7)$ & \\
\hline Awake and calm & $12(20.0)$ & $19(31.7)$ & $<0.001$ \\
\hline Drowsy & $5(8.3)$ & $34(56.7)$ & \\
\hline
\end{tabular}

$\mathrm{P}$ value determined by Chi-square test

\section{DISCUSSION}

Multiple arguments are given for and against the use of premedication with sedative drugs in children in order to minimize psychological trauma related to anaesthesia and surgery [11]. The present study was designed to test the effect of pre-operative medication with midazolam on overall amount of sevoflurane required for inhalational anaesthesia.

Total 120 paediatric patients were studied by dividing them into randomly groups: group $\mathrm{A}$ and group B. Patients of both groups were anaesthesized by sevoflurane. Alongside, group $B$ was given premedication with midazolam and group A was not given any premedication. Patents aged 1 to 7 years were considered for inclusion. Majority patient belonged age $3(28.3 \%)$ followed in second and third by age $4(25 \%)$ and age $5(23.3 \%)$. Mean age of the total population was $3.91 \pm 1.27$ years. Mean age of group A and group B patients are respectively $3.76 \pm 1.21$ and $4.06 \pm 1.32$ years. Both groups were age matched as distribution of patients was similar across groups. Köner et al. studied effects of hydroxyzine-midazolam premedication on sevoflurane-induced paediatric emergence agitation and included 84 children aging 1 to 7 years [12]. In their study mean age of groups were $2.5 \pm 1.6$ years and $2.3 \pm 1.4$ years, which is lower the findings of this study. 
In the study by Gómez B et al. mean age of the population was $3.17 \pm 1.94$ years, which was nearly similar to our study [13]. Cray et al. found mean 4.5 years in midazolam group and 4 years in placebo group [14]. Age distribution varied from study to study due to varying surgical procedure they are undergoing.

In this study $92.5 \%$ patients were male and $7.5 \%$ patients were female. Similarly Köner et al. found approximately $95 \%$ male and $5 \%$ female in their study population [12]. Gómez B et al. found slightly higher population male $(68.5 \%)$ than female $(31.5 \%)$ in their study [13]. This finding was expected as most of the surgeries were inguinal herniotomy, and ritual circumcision where male children were involved. In this study majority children had ASA grade I $(91.7 \%)$ and rest had grade II (8.3\%). Higher grades were purposefully excluded from the study, as only "day case surgeries" were included in this study and sick children would fail to fulfill the criteria of day surgery and discharge on the day of surgery. Distribution of grades were similar across groups- group A patients had 56 grade I and 4 grade II patients and Group B patients had 54 grade I and 6 grade II patients. This is concordant with the done by Sheta and AlSarheed majority children was ASA grade I, respectively 18 and 19 for medication and placebo groups and respectively 2 and 1 having grade II [15].

In this study parent separation characteristics of patients reveals that children who were not given premedication were more uncomfortable than who were given midazolam premedication $(88.3 \%$ vs $23.3 \%)$ The difference was statistically highly significant $(\mathrm{p}<0.001)$. Sheta and AlSarheed found a similar pattern [15]. They found that children who were given midazolam premedication had statistically significantly higher proportion of comfortable patients than controls. They also found with incremental dosage of midazolam from $0.5 \mathrm{mg} / \mathrm{kg}$ to $1 \mathrm{mg} / \mathrm{kg}$ was associated increased number of comfortable childrens. On the other hand Cray et al., did not find any effect of premedication with oral midazolam on pre-operative anxiety reduction [16]. Children are naturally afraid and anxious of unfamiliar environment, especially the operation room environment where sharp instruments and machineries are present.So they tend to resist when they are taken away from their parents. Anxiolytic medication reduces their anxiety and stress to some extent and make it easier to separate them from their parents.

At the current time, there are three major preoperative modalities for the reduction of anxiety in children: behavioral preparation programs of various kinds, parental presence during induction of anesthesia, and sedative premedication [17, 18]. But, multiple randomized controlled trial studies have found that midazolam is far superior to either preparation program or PPIA in terms of preoperative anxiety and compliance during induction of anesthesia [17]. Also in comparison to other sedative midazolam has the advantage of relatively short onset time associated with its oral, nasal, or rectal administration [19].

From the study results it is evident that premedication with midazolam provided better reduction in peri-operative anxiety, lesser consumption of sevoflurane in paediatric day case surgery.

\section{Conclusion}

Premedication with midazolam provided better parent separation criteria, smooth induction and postoperative recovery. Moreover, sevoflurane consumption was lesser with lower cost in these group compared to control.

\section{REERENCES}

1. Fox AJ, Rowbotham DJ. Anaesthesia. Bmj. 1999 Aug 28;319(7209):557-60.

2. Sigston PE, Jenkins AM, Jackson EA, Sury MR, Mackersie AM, Hatch DJ. Rapid inhalation induction in children: $8 \%$ sevoflurane compared with $5 \%$ halothane. British journal of anaesthesia. 1997 Apr 1;78(4):362-5.

3. Olokka KT and Ahonen J. Midazolam and other benzodiazepins. Handb Exp Pharmacol. 2008; 182: 335-360

4. Weldon BC, Watcha MF, White PF. Oral midazolam in children: effect of time and adjunctive therapy. Anesthesia and analgesia. 1992 Jul 1;75(1):51-5.

5. Coté CJ, Cohen IT, Suresh S, Rabb M, Rose JB, Weldon BC, Davis PJ, Bikhazi GB, Karl HW, Hummer KA, Hannallah RS. A comparison of three doses of commercially prepared oral midazolam syrup in children. Anesthesia \& Analgesia. 2002 Jan 1;94(1):37-43.

6. Kain ZN, Mayes L. Anxiety in children during the perioperative period. Child development and behavioral pediatrics. 1996:85-103.

7. Loughnan T, Akelisi-Yockopua L, Ageeling H, Goswami J. 6mg/kg Oral Ketamine Premedication in Children Results in Oversedation. Children. 2003 Jan;20(1).

8. Kain ZN, Mayes L. Anxiety in children during the perioperative period. Child development and behavioral pediatrics. 1996:85-103.

9. McCann ME, Kain ZN. The management of preoperative anxiety in children: an update. Anesthesia \& Analgesia. 2001 Jul 1;93(1):98-105.

10. Loughnan T, Akelisi-Yockopua L, Ageeling $\mathrm{H}$, Goswami J. 6mg/kg Oral Ketamine Premedication in Children Results in Oversedation. Children. 2003 Jan;20(1).

11. Rosenbaum A, Kain ZN, Larsson P, LÖNNQVIST PA, Wolf AR. The place of premedication in pediatric practice. Pediatric Anesthesia. 2009 Sep;19(9):817-28. 
12. Köner Ö, Türe H, Mercan A, Menda F, Sözübir S. Effects of hydroxyzine-midazolam premedication on sevoflurane-induced paediatric emergence agitation: a prospective randomised clinical trial. European Journal of Anaesthesiology (EJA). 2011 Sep 1;28(9):640-5.

13. Gómez LM, Ocampo F, Orozco JA, Caicedo J. Efficacy of anesthetic premedication in pediatric patients using oral midazolam and acetaminophen. Observational study. Revista Colombiana de Anestesiologia. 2013 Mar;41(1):4-9.

14. Cray SH, Dixon JL, Heard CM, Selsby DS. Oral midazolam premedication for paediatric day case patients. Pediatric Anesthesia. 1996 Jul;6(4):26570.

15. Sheta SA, AlSarheed M. Oral midazolam premedication for children undergoing general anaesthesia for dental care. International journal of pediatrics. 2009 Jan 1;2009.

16. Cray SH, Dixon JL, Heard CM, Selsby DS. Oral midazolam premedication for paediatric day case patients. Pediatric Anesthesia. 1996 Jul;6(4):26570.

17. McCann ME, Kain ZN. The management of preoperative anxiety in children: an update. Anesthesia \& Analgesia. 2001 Jul 1;93(1):98-105.

18. Kain ZN, Caldwell-Andrews AA. Psychological preparation of children undergoing surgery. Anesth Clinic NA. 2005;23:597-614.

19. Rosenbaum A, Kain ZN, Larsson P, LÖNNQVIST PA, Wolf AR. The place of premedication in pediatric practice. Pediatric Anesthesia. 2009 Sep;19(9):817-28. 